Les sources de l'Histoire des Mines : Nouveaux outils, Nouvelles approches

John Styles, The dress of the people. Everyday fashion in eighteenth-century England

New Haven and London, Yale University Press, 2007, 432 pages, illustrations.

Marco Belfanti

\title{
CpenEdition
}

Édition électronique

URL : http://journals.openedition.org/dht/708

DOI : $10.4000 /$ dht.708

ISSN : 1775-4194

Éditeur :

Centre d'histoire des techniques et de l'environnement du Cnam (CDHTE-Cnam), Société des élèves du CDHTE-Cnam

Édition imprimée

Date de publication : 1 décembre 2008

Pagination : 210-211

ISBN : $978-2-95-30779-2-6$

ISSN : 0417-8726

Référence électronique

Marco Belfanti, « John Styles, The dress of the people. Everyday fashion in eighteenth-century England», Documents pour l'histoire des techniques [En ligne], $16 \mid 2^{\mathrm{e}}$ semestre 2008, mis en ligne le 05 octobre 2010, consulté le 24 septembre 2020. URL : http://journals.openedition.org/dht/708 ; DOI : https:// doi.org/10.4000/dht.708

Ce document a été généré automatiquement le 24 septembre 2020.

(c) Tous droits réservés 


\section{John Styles, The dress of the people. Everyday fashion in eighteenth-century England}

New Haven and London, Yale University Press, 2007, 432 pages, illustrations.

Marco Belfanti

\section{RÉFÉRENCE}

John Styles, The dress of the people. Everyday fashion in eighteenth-century England, New Haven and London, Yale University Press, 2007, 432 pages, 128 illustrations.

1 C'est avec la publication, en 1982, du célèbre volume de Neil McKendrick, The consumer revolution in eighteenth-century England que s'est ouvert le débat historiographique sur la transition vers de nouveaux styles de vie au sein des sociétés européennes. McKendrick indiquait que c'est au XVIII ${ }^{e}$ siècle et en Angleterre que cette transformation se vérifie pour la première fois. Depuis, les historiens se sont confrontés sur ce thème, discutant de « révolution des consommations » en partant de positions souvent antithétiques : les optimistes contre les pessimistes. Le volume de John Styles s'avère très important car, construit sur une solide base empirique, il affronte avec un grand équilibre les questions historiographiques. De plus, il s'agit de la plus récente contribution sur le sujet.

2 John Styles offre une analyse détaillée des changements survenus dans l'habillement des classes populaires anglaises au cours du XVIII ${ }^{e}$ siècle en se basant sur des fonds archivistiques, des documents publiés, des pièces matérielles ainsi qu'un très riche appareil iconographique. Les récits de voyage décrivant l'Angleterre relèvent tous que l'habillement du menu peuple était bien plus riche et diversifié que celui des populations continentales. En effet, au cours du XVIII ${ }^{\mathrm{e}}$ siècle, à l'exception de la dernière décennie, les salaires réels anglais semblent plus élevés que ceux des autres 
pays européens : le revenu est donc déjà une explication aux différences existantes entre les garde-robes populaires anglaises et celles du continent. En province, même si la confection commençait à se diffuser de manière importante, le menu peuple achetait ses vêtements en recourant au large marché des vêtements de seconde main ou, plus souvent, achetait le tissu et s'adressait ensuite pour la confection aux tailleurs (pour l'homme) ou aux couturières mantuamakers (pour la femme), nombreux dans les petites villes et les villages anglais. À Londres, au contraire, le menu peuple bénéficiait de diverses possibilités afin de renouveler son habillement : il pouvait s'adresser aux vendeurs ambulants, aux fripiers vendant des habits usagés, aux petites boutiques confectionnant des vêtements sur mesure et, enfin, aux magasins spécialisés dans la vente de la confection.

$3 \mathrm{Si}$, d'un côté, l'évolution positive des salaires réels durant la plus grande part du siècle a sans aucun doute soutenu la tendance du menu peuple anglais à changer sa garde-robe - à ce sujet, John Styles souligne avec raison que cette pratique était étroitement liée au cycle de vie de la famille -, de l'autre côté, il faut souligner que - surtout à Londres - les nombreuses opportunités d'achat y attiraient de fait le menu peuple. La consommation anglaise relative à l'habillement parait donc due tant à l'évolution de la demande qu'à la vivacité de l'offre. Cette dernière devint particulièrement attractive grâce à la diffusion d'un tissu innovateur : le coton, fibre tout à la fois de la révolution industrielle et d'une révolution de l'habillement. Le coton pouvait en effet être décoré de diverses manières des plus attrayantes - imprimé, teint, peint - et était facilement lavable : ces caractéristiques en firent un produit très flexible, utilisable de diverses manières, dont certaines étaient à la portée de tous.

La demande et l'offre jouent un rôle essentiel, mais il est à noter l'existence de modalités importantes d'achat et de renouvellement de l'habillement populaire non réglées par des transactions monétaires, à savoir les dons, la charité, les récompenses/ prix. Le don du vêtement représente une habitude déjà ancienne et commune : partout en Europe, à partir du moins du XVI siècle, les princes faisaient cadeau d'habits aux courtisans comme signe de bienveillance et les nobles laissaient leurs vêtements usagés aux domestiques. Dans l'Angleterre du XVIII ${ }^{e}$ siècle, cette pratique demeure courante : des vêtements étaient offerts par les employeurs aux travailleurs, par les patrons aux domestiques, par les grands-parents et les oncles aux neveux. La charité peut, elle aussi, être considérée comme un don: elle se matérialise le plus souvent par la distribution d'habits aux pauvres. Dans certains cas, des vêtements constituaient les prix remportés lors des compétitions organisées pendant les foires de campagne. Jusqu'ici le terme "mode » a soigneusement été évité et ce, même s'il est indiqué dans le titre du volume, mais n'éludons pas plus longtemps la question: le menu peuple, auquel divers possibilités de changer sa garde-robe étaient proposées, était-il conscient du phénomène de la "mode" qui, par ses extravagances, faisait tourner la tête de la haute société de l'époque ? Y participait-il ? Les réponses données par John Styles à ce propos sont très subtiles. Le menu peuple s'avère sans aucun doute un observateur attentif des dynamiques de la mode et y participe d'une manière consciente, laquelle toutefois, n'engendrait pas nécessairement les typiques comportements d'émulation. La mode entrait dans les choix d'achat des classes populaires, mais ces dernières lui donnaient une interprétation particulière, dépendant de leurs propres moyens économiques et de leurs stratégies d'apparence : la popular fashion, comme la définit correctement John Styles. 


\section{AUTEURS}

\section{MARCO BELFANTI}

Université de Brescia (Italie) 